\title{
COMMUNITY ACQUIRED PNEUMONIA;
}

ASSESSMENT OF COMPONENTS OF DIRECT COST OF TREATMENT OF HOSPITALIZED PATIENTS IN KARACHI.

1. Ph.D

Associate Professor

Department Pharmacy

Ziauddin University Karachi Sindh

2. Ph.D

Professor

Department of Pharmaceutics

Hamdard University Karachi Sindh.

3. Ph.D

Professor

Department of Pharmacy Practice

Ziauddin University Karachi Sindh.

4. Ph.D

Associate Professor

Department of Pharmaceutics

University of Karachi Sindh.

5. Pharm D

Department of Pharmaceutics

Faculty of Pharmacy

Ziauddin University Karachi Sindh.

Correspondence Address:

Dr. Maqsood Ahmed Khan

Associate Professor

Department of Pharmacy Practice

Ziauddin University Karachi Sindh.

maqsoodkhan711@yahoo.com

Article received on:

31/08/2016

Accepted for publication:

15/04/2017

Received after proof reading:

05/06/2017

\section{Maqsood Ahmed Khan', Baqir Shyum Naqvi², Ali Akber Sial ${ }^{3}$, Farya Zafar ${ }^{4}$, Saquib Qureshi ${ }^{5}$}

ABSTRACT... Background: The treatment cost of community acquired pneumonia in Pakistan is a heavy economic burden for the society. Objectives: To assess the component of direct cost (ward cost, medication cost, laboratory and diagnosis cost and the length of stay cost) of treatment of community acquired pneumonia patients admitted in hospital ward. Study Design: Prospective study. Period: 15 months. Setting: Three private hospitals among these hospitals one of the hospital was a tertiary care university hospital situated in Karachi. Method: The study enrolled 514 patients and the patients were included from three private hospitals. Spearman correlation statistical tool was used to determine the correlation among variables Whitney $\mathrm{U}$ test was used to determine the cost in different groups. Results: A total of 514 cases were examined 322 cases were male and 192 cases were females. The CAP cases were mostly prevalent in patients with the age between 1-5 years (192), in male, low socioeconomic status and in unmarried patients. The mean length of hospital stay was 5.31 days found in patients admitted in the hospitals due to CAP. In this study the median medication cost of CAP per episode of treatment was Rs 2423(\$24.25), median laboratory diagnosis cost was found Rs 1310(\$13.11), median length of stay in hospital cost was found Rs $5700(\$ 57.04)$ and the median total cost of treatment was found Rs $9889(\$ 98.96)$. Conclusion: length of stay, laboratory diagnosis and the medication cost were the main components of direct cost of treatment of hospitalized cap patients. Age, comorbidity, PSI, laboratory diagnosis and length of stay was positively correlated with the direct cost of treatment of CAP. Gender difference was not correlated with the direct cost of treatment of CAP. The direct cost, drug cost, hospital stay cost increases as the pneumonia severity index increases, but in case of laboratory diagnosis cost is initially less in PSI I and increases in the PSI class II but remain same from PSI III to PSI V.

Key words: $\quad$ CAP: Community acquired pneumonia, LOS: Length of stay, PSI: Pneumonia severity index.

Article Citation: Khan MA, Naqvi BS, Sial AA, Zafar F, Qureshi S. Community acquired pneumonia; assessment of components of direct cost of treatment of hospitalized patients in Karachi. Professional Med J 2017;24(6):843-849.

DOI: $10.17957 / T P M J / 17.3543$

\section{INTRODUCTION}

Community acquired pneumonia (CAP) is a very severe disease and results dangerous outcomes. It is responsible for very high financial burden on the society. CAP is linked with high death rates and increased length of stay in hospitals. ${ }^{1}$ Therefore it is necessary to finds out less costly ways and logical management of CAP and it is only possible to discharge the patient as soon as possible in such a way that the patient should be protected from further any complication and repeated infection. ${ }^{2}$ High age patients mostly have CAP diseases. It is found that comorbidities are present with CAP diseases and usually comorbidities get intensified. This situation leads to high cost and increase the length of stay. Contrarily high age patients and those who are survived with the chronic illness faced more convoluted $\mathrm{CAP}^{3}$ It is estimated that CAP consumed 8.4-9.7 billion USD and 23 billion USD per year. CAP consumed 983 million USD as direct cost and 656 million USD as indirect cost in Germany. The factors that effects Cost includes patient compliance, productiveness, duration of hospital stay and access to ICU. ${ }^{4}$

Pneumonia severity index was developed by fine, who presented CAP in five categories. This rule 
explained that those patients who have less risk for death were recognized to three classes $(I, I I, I I I)$ of patients and the physician should considered to treat them in outpatients setting which minimize the economic burden is currently implemented globally. ${ }^{5}$

It was estimated that pneumonia consumed $£ 10$ billion in Europe as direct and indirect cost which almost more than $50 \%$ include the direct expense. Which categorized as $20 \%$ of all cases of CAP need in patients treatment and $90 \%$ consumed inpatients expense of direct cost and puts severe financial burden. ${ }^{6}$

Admission to hospital and duration of length of stay are the main element of expense in CAP treatment. A comprehensive knowledge of the elements effecting duration of hospital stay can guide to minimize duration of hospital stay and hospital admission. ${ }^{7}$ In developing countries like Pakistan very few studies are conducted on the cost of treatment of CAP.

The main objective of the current study was to analyses the parts of expense and the elements linked to the expense of management of CAP.

\section{METHODOLOGY}

\section{Study subject}

It was a prospective observational study was carried out over 15 months period in three private hospitals among these hospitals one of the hospital was a tertiary care university hospital situated in Karachi. The capacity of these hospitals was 200 beds, 120 beds and 300 beds. Pneumonia was defined as a new pulmonary infiltrate together with symptoms and signs of a lower respiratory tract infection. ${ }^{8}$

\section{Inclusive criteria}

Those patients were selected who were clinically diagnosed with CAP.

\section{Exclusive criteria}

HIV patients, tuberculosis patients were not included in this study, and the patients who were admitted to the ICU department were not included in this study.

\section{Data collection}

Following Demographical data and other patient's related data were assessed: patient gender, age, socioeconomic status, comorbidity, and pneumonia severity index and hospital length of stay. According to Fine et al 1997. patient were classified in five danger category(range, I-V). ${ }^{5}$ Specific comorbidity feature consist of chronic obstructive pulmonary diseases (COPD), asthma, cardiovascular illnesses, renal, hepatic disease, diabetes mellitus, with CAP. Length of stay (LOS) was defined as the number of days between admission and discharge.

\section{Cost calculation}

Direct cost assessed includes those linked to utilization of healthcare resources like diagnostic and laboratory tests, management and duration of hospital stay. The indirect expense linked to work days fails to attend or moving to hospital was not examined. The tests were categorized in to three types as mention below;

1. Blood tests: complete blood count, biochemistry.

2. Microbiological studies: blood and sputum culture.

3. Radiological studies: plain radiographs.

The treatment of CAP was categorized as treatment of CAP and other treatment relevant to subside the symptoms of CAP. Comorbidity, concomitant treatment and management of complication cost was not included. Cost based on these drugs used, the frequency of drugs utilized how to administer (oral, intravenous, intramuscular, subcutaneous or inhaled) were recorded. The duration of length of stay was estimated total duration of hospitalization, from admission to the hospital till the day of release.

The estimated cost category were classified as follows.1. Expense of medication. 2. Length of stay at ward cost. 3. Expense of laboratory tests. 4. Cost of diagnostic tests. All expenses were 1st measures in Pakistani rupees and then 
converted to US dollar for the year 2012.All the above cost category were added to get the total final cost. The medication cost was estimated as the median cost of the drug (data provided by the pharmacy services of the hospitals. The expense of laboratory, radiology and other associated expenses were found from the official fee of the hospitals. The cost per day stay was obtained from the hospitals administration departments. we used the average dollar rate(1US $\$=99.93 R s$ ) during study period for the conversion of Rupees to US dollar.

\section{Statistical analysis}

All the data arranged on the excel sheet and were analyzed and processed using SPSS version 15. A descriptive analysis was performed by means of SPSS 15. Data was analyzed with the help of SPSS. Then correlation was found between variables by using spearman correlation. Mannwithney $\mathrm{u}$ test was used to determine the difference in cost among different groups. All $P$ values of $<0.05$ were considered statistically significant.

\section{Ethical approval}

The study was approved from the Board of Advance Study and Research (BASR) of the University of Karachi and the local committee of the hospital. Permission was obtained from the administration of the hospital. Informed consent was not taken from the patients because there was no involvement affecting either physicians' management resolution or the patients.

\section{RESULTS}

Table-I summarized the demographic characteristics, comorbidity, pneumonia severity index and length of stay of patients hospitalized due to CAP. Table-I represents that a total of 514 cases were examined 322 cases were male and 192 cases were females. The CAP cases were mostly prevalent in patients with the age between 1-5 years (192) in male, low socioeconomic status and in unmarried patients. Comorbidity found in CAP patients were hypertension, diabetes, liver diseases, renal diseases, pulmonary diseases, chronic obstructive pulmonary diseases(COPD), central nervous system diseases (CNS), cardiovascular diseases (CVD).The mostly occurred comorbid condition found in CAP patients was hypertension. The frequency of CAP with the pneumonia severity index were as follows patients with PSI class I were (319), PSI class II (93), PSI class III (59), PSI class IV 23 and the patients with the PSI class $V$ were 20.The mean length of hospital stay was 5.31days found in patients admitted in the hospitals due to CAP.

\begin{tabular}{|c|c|}
\hline Subjects $\mathrm{n}$ & 514 \\
\hline \multicolumn{2}{|l|}{ Age in years } \\
\hline $1-5$ years & 192 \\
\hline 6-20years & 72 \\
\hline $21-30$ years & 42 \\
\hline 31-40years & 28 \\
\hline 41-50years & 30 \\
\hline $51-60$ years & 29 \\
\hline 61-70years & 51 \\
\hline 71-80years & 36 \\
\hline 81-90years & 34 \\
\hline \multicolumn{2}{|l|}{ gender } \\
\hline Male/female & $322 / 192$ \\
\hline \multicolumn{2}{|l|}{ Socioeconomic status } \\
\hline Low/middle/high & $335 / 131 / 48$ \\
\hline \multicolumn{2}{|l|}{ Marital status } \\
\hline Married/unmarried & $218 / 296$ \\
\hline \multicolumn{2}{|l|}{ COMORBIDITY } \\
\hline Hypertension & 79 \\
\hline Diabetes & 66 \\
\hline Liver diseases & 7 \\
\hline Renal diseases & 8 \\
\hline Pulmonary & 10 \\
\hline COPD & 7 \\
\hline CNS & 4 \\
\hline CVD & 4 \\
\hline Patients without comorbidity & 329 \\
\hline \multicolumn{2}{|l|}{ Pneumonia severity index } \\
\hline PSI I & 319 \\
\hline PSI II & 93 \\
\hline PSI III & 59 \\
\hline PSI IV & 23 \\
\hline PSI V & 20 \\
\hline Mean LOS & 5.31 days \\
\hline \multicolumn{2}{|c|}{$\begin{array}{l}\text { Table-I. Characteristics } \\
\text { Note: LOS: length of stay }\end{array}$} \\
\hline
\end{tabular}

\section{Cost Results}

Figure-1 depicts the components of direct 
cost of treatment of CAP. In this study cost per episode of CAP was the median medication cost of CAP treatment was Rs 2423(\$24.35), median laboratory diagnosis cost was found Rs 1310 (\$13.11), median length of stay in hospital cost was found Rs 5700(\$57.04) and the median total cost of treatment was found Rs 9889 (\$98.96).

Cost in US Dollar

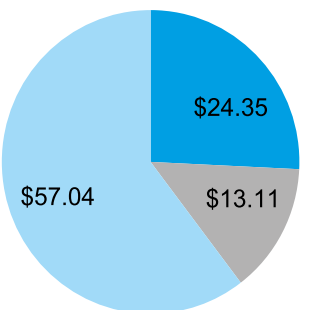

median medication

cost

median laboratory and diagnosis cost

median hospital length of stay cost

\section{Correlation}

Spearman correlation statistical analysis was used to determine the correlation. Age, comorbidity, PSI, laboratory diagnosis and length of stay was positively correlated with the direct cost of treatment of CAP. Gender difference was not correlated with the direct cost of treatment of CAP. Table-II shows the different cost categories based on PSI class and depicts that there is strong positive correlation found between PSI and the direct cost of treatment of CAP. The direct cost, drug cost, hospital stay cost increases as the pneumonia severity index increases, but in case of laboratory diagnosis cost is initially less in PSI I and increases in the PSI class II but remain same from PSI III to PSI V.

Figure-1. Total direct median cost of treatment

\begin{tabular}{|c|c|c|c|c|c|c|c|}
\hline \multicolumn{8}{|c|}{ PSI Class } \\
\hline & $\begin{array}{c}\text { Total median } \\
\text { cost }\end{array}$ & PSI I & PSI II & PSI III & PSI IV & PSI V & P-value \\
\hline Medication cost & 2423(\$24.35) & $\begin{array}{l}1860 \\
(\$ 18.61)\end{array}$ & $\begin{array}{l}5281 \\
(\$ 52.85)\end{array}$ & $\begin{array}{l}4803 \\
(\$ 48.06)\end{array}$ & $\begin{array}{l}13744 \\
(\$ 137.54)\end{array}$ & $\begin{array}{l}25440 \\
(\$ 254.58)\end{array}$ & 0.000 \\
\hline $\begin{array}{l}\text { Laboratory } \\
\text { diagnosis cost }\end{array}$ & $1310(\$ 13.11)$ & $\begin{array}{l}660 \\
(\$ 6.61)\end{array}$ & $\begin{array}{l}1310 \\
(\$ 13.11)\end{array}$ & $\begin{array}{l}1310 \\
(\$ 13.11)\end{array}$ & $\begin{array}{l}1310 \\
(\$ 13.11)\end{array}$ & $\begin{array}{l}1310 \\
(\$ 13.11)\end{array}$ & 0.000 \\
\hline $\begin{array}{l}\text { Hospital stay } \\
\text { cost }\end{array}$ & $5700(\$ 57.04)$ & $\begin{array}{l}5400 \\
(\$ 54.04)\end{array}$ & $\begin{array}{l}9000 \\
(\$ 90.06)\end{array}$ & $\begin{array}{l}9000 \\
(\$ 90.06)\end{array}$ & $\begin{array}{l}22800 \\
(\$ 228.16)\end{array}$ & $\begin{array}{l}34200 \\
(\$ 242.24)\end{array}$ & 0.000 \\
\hline Total CAP cost & $9889(\$ 98.96)$ & $\begin{array}{l}8007 \\
(\$ 80.13)\end{array}$ & $\begin{array}{l}14853 \\
(\$ 148.63)\end{array}$ & $\begin{array}{l}14930 \\
(\$ 149.41)\end{array}$ & $\begin{array}{l}46096 \\
(\$ 461.28)\end{array}$ & $\begin{array}{l}59851 \\
(\$ 598.93)\end{array}$ & 0.000 \\
\hline \multicolumn{8}{|c|}{ Table-II. Cost based of pneumonia severity index in Rupees and US\$ } \\
\hline
\end{tabular}

Table-III summarized the cost, based on age, gender and comorbidity. Mann-withney $u$ test was used to determine the difference in cost among different groups. It was found that patient with the age $\leq 70$ years consumed less median cost Rs 9015)(\$90.21) and the patients with the age $>70$ years consumed greater cost median cost Rs 16101(\$161.12)) $(p=0.00)$. It was found that females patients were consumed greater cost than the male, but statistically not reach significant $(p=0.491)$. CAP patients with comorbidity consumed the cost as follows with hypertension median cost per episode Rs 17272(\$172.84), with diabetes Rs 15802(\$158.13), with liver diseases Rs $8002(\$ 80.07)$, with renal diseases Rs 12355(\$123.64), with pulmonary diseases Rs 48272(\$483.06), with COPD Rs 13134(\$131.43), with CNS, Rs 14724(\$147.34), with CVD consumed Rs 61100(\$611.43). The highest cost incurred in those CAP patient who were with the diseases of CVD and the CAP patient possessed no comorbidity consumed a median cost Rs 8086(\$80.92) per episode of CAP. It was confirmed that patient with comorbidity consumed greater cost than the patient have no comorbid condition.

\section{DISCUSSION}

The major information of the present study can be summarized as follows the median total expense of management of hospitalized CAP patients was Rs $9889(\$ 98.96)$, median length 
of stay generated the highest direct cost Rs $5700(\$ 57.04)$. Patients with the comorbidity of CVD consumed the highest cost as compare to the patients possessed other comorbidity. Age, Pneumonia severity index, length of stay and comorbidity is positively correlated with the direct cost of treatment of CAP.

\begin{tabular}{|l|l|}
\hline \multicolumn{1}{|c|}{ Characteristics } & $\begin{array}{c}\text { Median direct Cost of } \\
\text { treatment of CAP in Rs } \\
\text { and US\$ }\end{array}$ \\
\hline Age $\leq 70$ years & $9015(\$ 90.21)$ \\
\hline Age $>70$ years & $16101(\$ 161.12)$ \\
\hline Gender & $9307(\$ 93.14)$ \\
\hline Male & $10985(\$ 109.93)$ \\
\hline female & \\
\hline $\begin{array}{l}\text { Cost based on comorbidity } \\
\text { of the patients }\end{array}$ & $17272(\$ 172.84)$ \\
\hline Hypertension & $15802(\$ 158.13)$ \\
\hline Diabetes & $8002(\$ 80.07)$ \\
\hline Liver diseases & $12355(\$ 123.64)$ \\
\hline Renal diseases & $48272(\$ 483.06)$ \\
\hline Pulmonary diseases & $13134(\$ 131.43)$ \\
\hline COPD & $14724(\$ 147.34)$ \\
\hline CNS & $61100(611.43)$ \\
\hline CVD & $8086(\$ 80.92)$ \\
\hline Without comorbidity & Table-III Cost Based on $\mathrm{Age}$ and Demography \\
\hline
\end{tabular}

It is reported that in the united states of America (USA) around 3-4 million people diagnosed with CAP and one million are hospitalized due to CAP. The yearly expense of CAP management present dissimilar facts as 8.4-9.7 billion USD and 23 billion USD. Total direct expense in Germany due to CAP estimated was 983 million USD and indirect expense were 656 million USD. Following factors that effects expenses are patient compliance, efficacy, duration of stay in hospital, and admission to intensive care unit (ICU). ${ }^{4}$

The direct cost calculated in Europe varied from $€ 1,333$ in Germany to $€ 2,550-7,650$ in the UK. Inspite of that the cost in US hospitals were significantly higher than the cost in the European hospital regardless of longer average stay. In a prospective study conducted by Fine et al in four hospital in USA and determined a median total expense of $€ 4,468$ for the patients admitted in hospitals due to $\mathrm{CAP}^{3}$

In the present study, an elevation in total expense was observed for patients with increased severity of CAP, and for patients with comorbidity. Similar results were found in the study conducted by (Reyes et al in 2008). which expressed that more severe CAP cases resulted to more cost. ${ }^{8}$ Described considerable expense in patients with severe CAP and need admission to ICU, as compare to those patients with less severe pneumonia it is because of longer duration of stay at hospital.

Inspite of the fact that the current study did not considered the ICU cases. An elevated expense in patients with high PSI was found ,because of higher number of diagnosis tests and a longer duration of stay was established also reported that patients 65 years of age with comorbidity shown more complications. ${ }^{9}$ Although, this discovery is also described by the fact that the $\mathrm{PSI}$ was elevated in this group.

In the present study we determined total direct median cost Rs 9889(\$98.96) per episode of CAP and duration of hospital stay produced the highest expense per episode of CAP Rs 5700(\$57.04). Comparing to other study it was determined the median total cost of hospitalized CAP patients was $€ 1,683$, duration of stay produced the highest direct cost $(69.3 \%)^{3}$, and in another study it determined the total hospital costs $\$ 556.5 .^{10}$

In the present study the median expense of medication per episode of CAP disease was Rs 2423(\$24.25). comparing the other study it was that the determined average costs of medicine was 484.59 Euro $^{4}$ and another study determined Pharmacy costs $\$ 257 .{ }^{10}$ Our study shows much less cost of medicine treatment than these studies.

In the present study we determined the cost based on PSI classes. The median direct cost determined for class I was Rs $8007(\$ 80.13)$, for class II 14853(\$148.63) class III 14930(\$149.41), class IV Rs 46096(\$461.28), class V Rs 
59851 (\$598.93). In our study as the severity of the disease increases the cost of treatment of CAP also increases. Comparing to a study similar pattern was found in a way that as the severity of disease increases cost also increases and determined the cost based on PSI for class I it was $€ 1531$, class II €1602, class III, €1630, class IV, $€ 1804$, class $\mathrm{€} € 1972 .^{3}$

In the present study we found that the cost was higher in the patients with the age group of Age $>70$ years median expense determined was Rs 16101(\$161.12) and median expense was $9015(\$ 90.21)$ in the patients of Age $\leq 70$ years. Comparing to other study it was determined an inclination towards increased expense among patients aged 70 years, the difference did not reach statistical significance. ${ }^{3}$ But in other study it was found importantly higher expense in patients 65 years of age, but no details were provided on the effect of comorbidity and severity. ${ }^{11}$

In the present study it was found that the patient with no comorbidity consumed less cost as compare to the patients with the comorbidity and the cost was found much higher in patient with the comorbidity of cardiovascular disease. Comparing to other study it was determined that co-morbid diseases increased the total cost, but at higher ages ( $>65$ year) there was no effect on the total cost ${ }^{4}$ but in 2001 in another study it was; described that age and co-morbid disease had no effect on the total cost of CAP. ${ }^{12}$

In the present study it was found the mean LOS was 5.31 days comparing to other disease it was (Reyes et al 2008) determined the median LOS 9 days for CAP patient ${ }^{3}$ and this represents higher length of stay than our present study. There were limitation in our study. First we did not consider patients stay in ICU and relevant cost. Secondly we did not include the complicated CAP cases Third the mortality of the CAP patients did not recorded.

In conclusion age greater than 70 years, PSI class, comorbidity and hospital stay are the factors contribute in greater cost and medication cost, hospital length of stay cost, number of diagnosis and its cost are the major component of cost for the treatment of CAP in hospitalized patients. Copyright (C) 15 Apr, 2017.

\section{REFERENCES}

1. Sato R, Gomez Rey G, Nelson S et al. Communityacquired pneumonia episode costs by age and risk in commercially insured US adults aged $\geq \mathbf{5 0}$ years. Appl Health Econ Health Policy 2013; 11(3):251-8.

2. Suter-Widmer I, Christ-Crain M, Zimmerli $W$ et al. Predictors for length of hospital stay in patients with community-acquired Pneumonia: Results from a Swiss Multicenter study BMC Pulmonary Medicine 2012, 12:21.

3. Reyes S, Martinez R, Vallés JM et al. Determinants of hospital costs in community-acquired pneumonia Eur Respir J 2008; 31: 1061-1067.

4. Doruk S, Tertemiz KC, Kömüs $\mathrm{N}$ et al. Community acquired pneumonia and direct hospital cost Tuberk Toraks 2009; 57(1): 48-55.

5. Fine MJ, Auble TE, Yearly DM A prediction rule to identify low-risk patients with community-acquired pneumonia N Engl J Med 1997 Jan 23;336(4):243-50.

6. Ott SR, Hauptmeier BM, Ernen $C$ et al. Treatment failure in pneumonia: impact of antibiotic treatment and cost analysis. Eur Respir J 2012; 39: 611-618.

7. Huang JQ, Hooper PM, Marrie TJ. Factors associated with length of stay in hospital for suspected community-acquired pneumonia. Can Respir J 2006; 13(6):317-324.

8. Bauer TT, Welte T, Ernen C et al. Cost analyses of community-acquired pneumonia from the hospital perspective Chest 2005; 128(4):2238-46.

9. Kaplan V, Angus DC, Griffin MF et al. Hospitalized community acquired pneumonia in the elderly: ageand sex-related patterns of care and outcome in the United States. Am J Respir Crit Care Med 2002; 165: 766-772.

10. Zhou QT, He B, Zhu H. Potential for Cost-Savings in the Care of Hospitalized Low-Risk CommunityAcquired Pneumonia Patients in China. Value Health. 2009; 12(1):40-6.

11. Bartolome' M, Almirall J, Morera J, et al. A populationbased study of the costs of care for community-acquired pneumonia. Eur Respir J 2004; 23: 610-616.

12. Yark T, Yazicioglu PM, Stamping E et al. Community 


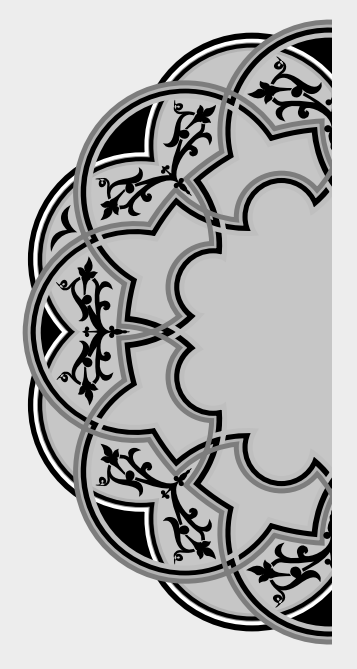

\title{
"Never let your fear decide your future."
}

\author{
Unknown
}

\section{AUTHORSHIP AND CONTRIBUTION DECLARATION}

\begin{tabular}{|c|c|c|c|}
\hline Sr. \# & Author-s Full Name & Contribution to the paper & Author $=\mathbf{s}$ Signature \\
\hline 1 & Dr. Maqsood Ahmed Khan & Principal Investigator & \\
\hline 2 & Dr. Baqir Shyum Naqvi & Supervisor the result & \\
\hline 3 & Prof. Dr. Ali Akber Sial & Support and guideline & \\
\hline 4 & Dr. Farya Zafar & Data analysis & \\
\hline 5 & Dr. Saquib Qureshi & Support and Data collection & \\
\hline
\end{tabular}

